\title{
The Aristotelian Explanation of the Halo
}

\author{
Monte Ransome Johnson
}

Occasionally one sees a perfectly circular illumination around a heavenly body such as the moon; the same kind of thing is sometimes seen around the sun as well, although we do not notice it very often because we are accustomed to averting our eyes away from the sun. The Greeks called such things the 'halo' ( $\dot{\eta} \alpha \lambda \omega \varsigma)$, perhaps because of their resemblance to a circular threshing floor ( $(\alpha \lambda \omega \varsigma)$. Aristotle tried to explain why halos always appear to form a complete circle, unlike related meteorological phenomena such as rainbows, parhelia, and 'rods'. ${ }^{1}$ In so doing

1 It is not perfectly clear how the modern names for meteorological phenomena correspond to the terms used by Aristotle. The i $\iota_{\varsigma}$ is obviously the rainbow, although it should be pointed out that a complete rainbow does form a circle. This fact was apparently not observed by Aristotle and even denied by him (371b26-7). In modern scientific parlance, the term 'halo' refers to the set of all optical phenomena produced by ice crystals in clouds (both circular and noncircular), of which the most frequently observed by far is the $22^{\circ}$ halo, but the modern term refers also to the (more rare) $46^{\circ}$ halo and odd radius halos (which are circular), as well as noncircular phenomena like parhelia and arcs. What Aristotle calls $\pi \alpha \rho \lambda^{\prime} \iota \mathrm{\iota}$ are what are now called 'mock suns', 'sun dogs', or simply parhelia. Least clear is

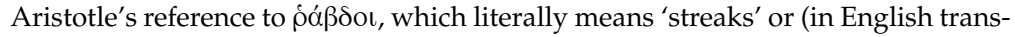
lations) 'rods'; but unlike 'halos' and 'parhelia', the term is no longer in use. The phenomenon has plausibly been interpreted as the halo phenomena now called Lowitz arcs (see J. Groisard, Aristote, Météorologiques: Introduction, traduction, notes et bibliographie (Paris: Flammarion 2008), 271n1). Lowitz arcs are very rare phenomena, and until recently even their existence was doubted, although there is by now definitive photographic proof and theoretical models to explain them (see L. Cowley, www.atoptics.co.uk). Interpreters of the Meteorology have universally assumed that Aristotle has in mind the $22^{\circ}$ halo, but he may as well have had the $46^{\circ}$ halo in mind, and even coronae, which are caused by diffraction due to water 
he describes one of the earliest lettered geometrical diagrams, representing the relative positions of the observer, the halo, and a heavenly body.

For an Aristotelian observer, an immediately striking thing about the halo is that it is indeed perfectly circular but nevertheless an apparently sublunary phenomenon; for similar reasons it is striking that Aristotle explains the phenomena by supposing rectilinear rays to extend between an observer's earthly eye through the intermediate zones of water and air, so far as a heavenly body such as the sun. Besides being of intrinsic interest, Aristotle's treatment of the halo offers a concrete case study of scientific explanation, of the conformity of Aristotle's scientific practice with the method described in the Posterior Analytics, and of the application of mathematics to natural science in antiquity. It is further a case of explanation in the so-called subalternate (or subordinate or mixed) sciences, and so of the controversial practice of kind-crossing. ${ }^{2}$

droplets, not refraction by ice crystals like 'halos' in the modern sense. These possibilities will be discussed below.

2 Current research has demonstrated the significant influence, importance, and difficulties of Aristotle's notion of subalternate sciences (also called 'subordinate' or 'mixed' sciences). Richard D. McKirahan Jr. shows how the contents and methods of Euclid's Optics 'stand in the various relations to his Elements in which Aristotle states that optics stands to geometry' ('Aristotle's Subordinate Sciences', British Journal for the History of Science 11 [1978] 197-220, at 199). McKirahan describes his goal as trying 'to develop some of Aristotle's own suggestions in greater detail than we find in the text, but along lines which he would accept' (206) and I try to do the same here. A similar contribution is made in James G. Lennox's discussion of the subalternation relation between geometry and optics in his examination of Aristotle's influence on Galileo's "new sciences" ('Aristotle, Galileo, and "Mixed Sciences" ' in W. A. Wallace, ed. Reinterpreting Galileo (Washington, DC: Catholic University of America Press 1986) 29-51). Specifically, Lennox examines Aristotle's explanation of the fact that the rainbow never forms an arc greater than a semicircle in the Meteorology; in the present paper I extend this research to the halo. Some details of the mediation between the ancient sources and Galileo on the issue of subalternate sciences have been filled in by Steven J. Livesey ('Science and Theology in the Fourteenth Century: the subalternate sciences in the Oxford Commentaries on the Sentences', Synthese 83 [1990] 273-292). In a recent far-reaching study, R. J. Hankinson puts on the table translations and careful analyses of all the key primary texts in a searching examination of Aristotle's prohibition on the use of demonstrations in one science drawing on principles proper to another science in the Posterior Analytics ('Aristotle on Kind-Crossing', in R. W. Sharples, ed. Philosophy and the Sciences in Antiquity [Burlington, VT: Ashgate 2005] 23-54). Besides elucidating a number of stock examples of subalternate sciences from the Posterior Analytics, Hankinson also examined in detail a 'kind-crossing' explanation between two non-subalternate sciences suggested by Aristotle's cryptic remark: 
Some modern commentators have not been at all happy with Aristotle's explanation of the halo. F. Poske was influential on subsequent commentators when he remarked: 'Die geometrische Construction deckt sich allenfalls mit dem rohesten sinnlichen Eindruck, entspricht aber durchaus nicht der Wirklichkeit. Die Demonstration, als eine Erklärung in unserem Sinne betrachtet, ist in fast allen Theilen so verfehlt, dass es sich kaum der Mühe zu lohnen scheint, von derselben Kenntniss zu nehmen. ${ }^{3}$ His estimation was approved by O. Gilbert in his comprehensive study of Greek meteorology, who suggests that Poske 'der hierfür den einzig richtigen Gesichtspunkt geltend gemacht hat.' E. W. Webster, in his note on the passage in the Oxford Translation of the Meteorology, cites both Poske and Gilbert before remarking of the explanation that: 'this begs the question and stultifies the succeeding discussion..$^{5}$ H. D. P. Lee, in a note to the Loeb translation of the same passage was even briefer in representing this view: 'here Aristotle in effect assumes what he is setting out to prove. ${ }^{\prime 6}$

My own conclusions are more in line with those of Thomas Heath, who discerned no obvious problems in his own exposition of the Aristotelian passage; with Aydin Sayili and Carl Boyer, who were impressed with the remarkable sophistication of Meteorology III as the first attempt to apply geometrical techniques to the explanation of terrestrial phenomena; and with Liba Taub, who argues that the explanation of the halo in particular is an important and interesting contribution to the history of meteorology as a science. ${ }^{7}$ I argue that Aristotle's explana-

'for it is for the doctor to know that circular wounds heal more slowly, but for the geometer to know why' (I 13, 79a14-16).

3 'Die Erklärung des Regenbogens bei Aristoteles', Historisch-literarische Abtheilung, Zeitschrift für Mathmatik und Physik 28 (1883) 134-138, at 137

4 Die meteorologischen Theorieen der griechischen Altertums (Leipzig: Teubner 1907), 601

5 The Works of Aristotle Translated into English Volume III (Oxford: Oxford University Press 1931), at 373a

6 Aristotle Meteorologica (Cambridge, MA: Harvard University Press 1952), 249 note a

7 T. Heath, Mathematics in Aristotle (Oxford: Oxford University Press 1949), 61 and 180-1; A. M. Sayili, 'The Aristotelian explanation of the rainbow', Isis 30 (1939) 66-83; C. B. Boyer, The Rainbow: from myth to mathematics (Princeton, NJ: Princeton University Press 1959), 46 and passim; L. Taub, Ancient Meteorology (London: Routledge 2003), 108-15 
tion shows an interesting quantitative side of his scientific method; is superior to all other explanations of the same phenomena offered by his predecessors; and is in a way still viable and in fact has had a direct influence on modern scientific explanations of the halo, including those found in textbooks on atmospheric optics.

\section{I}

Aristotle's treatment of the halo represents a steady development of the seminal theories of his predecessors, and in fact makes an important advance that was not furthered by his successors until Descartes and Huygens. ${ }^{8}$ Xenophanes of Colophon is celebrated for having offered a naturalistic account of the most spectacular phenomenon associated by the poets with the goddess Iris, the rainbow. (Iris is usually identified with the rainbow, but is often connected with other meteorological phenomena, as in Aristotle.') Xenophanes argued that the Iris was in reality a cloud. ${ }^{10}$ Anaximenes argued that it was the impact of the sun's rays on the cloud that produces the Iris and is responsible for its color, and it is possible that he had in mind something like reflection, although the available evidence does not make this clear. ${ }^{11}$ It is most likely that ac-

8 His contribution to this aspect of meteorological theory could be compared with his similarly important and long unsurpassed treatment of aurora phenomena, not improved upon until modern science as R. Stothers has shown in 'Ancient aurorae' Isis 70 (1979) 85-95.

9 Boyer, The Rainbow, 23; cf. J. H. Lesher, Xenophanes of Colophon (Toronto: University of Toronto Press 1992), 139.

10 'She who they call Iris, this too is by nature a cloud, purple, red, and greenish-yellow to behold' (H. Diels and W. Kranz, Die Fragmente der Vorsokratiker (6th ed. Berlin: Weidmann, 1951) [DK] 21B32 = Scholium on Il 11 27). See Lesher, Xenophanes, 139-44 for an excellent discussion.

11 'Anaximenes says that Iris comes about from light of the sun ( $\alpha v \gamma \gamma \sigma \mu o ́ v)$ against a cloud dense, thick, and dark thanks to the inability of the rays to cut through to the edge when they have been set up against it' (DK 13A18 = Aetius III.5.10 = H. Diels, Doxographi Graeci, Berlin: Reimer 1879 [DG], 373). 'Anaximenes says that Iris comes about when the beams of the sun fall on thick and dense air. Hence the first part of it appears red, being burnt by the rays of the sun, while the other part is dark, because of the wetness. And he says that a rainbow comes about at night by the moon, but not often, because there is not constantly a full moon, and its light is weaker than that of the sun' (DK 13A18 = Schol Arati v $940=$ Diels DG, 231). Phil Horky suggested to me that one could possibly understand $\alpha \hat{\gamma} \gamma \alpha \sigma \mu o ́ v$ in 
cording to both of these accounts the Iris is treated a cloud, some kind of modification of air. Anaxagoras seems to have been the first one to clearly go beyond these accounts by suggesting that the effect is caused by 'shining back' ( $\alpha \nu \tau \iota \lambda \alpha \dot{\alpha} \mu \pi \mathrm{ov})$, meaning reflection; and he further offered an account (the earliest, so far as I can tell) of related halo phenomenon - parhelia or mock suns - along the same lines. ${ }^{12}$

For this precious information we are dependent on the doxographical tradition of Aëtius and so our evidence is overly brief, truncated, and sketchy. But Aristotle developed these views by making it clear that the rainbow and the halo are not substantial objects, not a kind of cloud or mist, but rather an optical effect or illusion that appears to the observer due to the reflection of visual rays in tiny mirrors of air and water suspended in the region between the luminescent body and the eye. This point is still not grasped in twenty-first century popular understanding of rainbows and halos. Unlike a cloud or any solid body or substance, which must look different from different perspectives, the halo appears the same to all those to whom it appears - a complete circle - and Aristotle is at pains to explain why it always appears as a complete circle ( $\kappa \cup ́ \kappa \lambda \circ \varsigma$ ö $\lambda \mathrm{O}$ ). Aristotle focuses on the geometricaloptical dimension of the problem, on the nature of the tiny, uniform constituents of the cloud and the angle at which they shine light.

This focus turns out to be the key to the explanation of the circular halos, both the relatively common $22^{\circ}$ halo and the much rarer $46^{\circ}$ halo, which are due to refraction of sunlight or moonlight through prismatic ice crystals suspended in the atmosphere. A similar explanation in theory applies to the relatively common phenomenon of coronae, but these are due rather to diffraction caused by water droplets. ${ }^{13}$ Now Aristotle does not clearly distinguish these phenomena, halos and coronae. We

the first quotation as some kind of reflection (see LSJ, s.v.), in which case Anaxagoras would be following Anaximines and not the originator of the reflection theory (see below). But the second quotation does not seem to support such a reading.

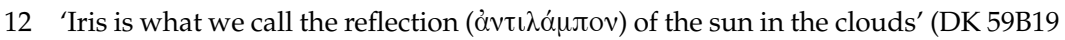
= Scholium on Il 17.547). 'Anaxagoras: [the rainbow is] reflection from a thick cloud of radiance of the sun, and it always stands straight across from the same

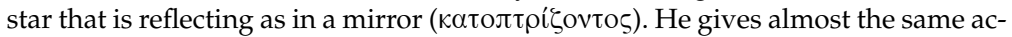
count of the things that are called parhelia, which come about near the Black Sea' (Aetius III.5.11 = Diels DG, 373-4).

13 See L. Cowley et al., 'Rings around the sun and moon: coronae and diffraction', Physics Education 40 (2005) 51-59. 
would seem to be able to eliminate the possibility of a reference to coronae by the fact that they often show a variety of colors, since Aristotle describes the halo as lacking variety of colors in contradistinction to the rainbow (373b35-4a3, cf. 372b24-5); but this cannot be definitive, because even the $22^{\circ}$ halo occasionally shows an reddish inner edge and bluish outer edge (although this is rare, and the colors are generally indistinct and wash out to a pale white). On the other hand, Aristotle describes halos around not just the sun and the moon, but other stars as well, and while coronae could possibly be seen around bright stars or planets, the $22^{\circ}$ and $46^{\circ}$ halos would be much too faint.

A related point that deserves emphasis is that Aristotle does not distinguish reflection from refraction or diffraction, and this is key to the contemporary explanation of such phenomena. ${ }^{14}$ Randomly disbursed mirrors in the atmosphere would not reflect a halo but rather something like a diffused brightness throughout the region, rather like coronae, in fact, and unlike halos. ${ }^{15}$ It is due to the refraction of light at a constant angle that randomly disbursed ice crystals are illuminated at $22^{\circ}$ from the observer in the smaller halo. In any case, Aristotle did understand the key to the problem was to conceive of the halo as an optical illusion due to 'uniform and small' bodies altering the course of light (or 'sight' as it were, more on this below). Where others had tried to say that some physical mass was formed into a circular shape, Aristotle is arguing that the halo is a reflection phenomenon and that it is the reflection that is circular, not the cloud or mist or whatever it is in which the reflection is occurring. Aristotle shifted from offering an explanation in terms of a specific shape of cloud to an explanation in terms of the movement and reflection of visual rays. In so doing, he developed an explanation which is the basis of the explanation found in modern textbooks on atmospheric optics, according to which circular halos are caused by tiny randomly dispersed column-shaped hexagonal ice crystals refracting light at $22^{\circ}$ on every plane between the sun or moon and an observer (more on this below).

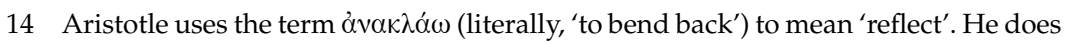

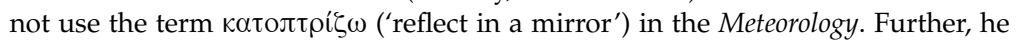
does not offer a mathematical treatment of mirrors which reflect images (as Boyer rightly notes, The Rainbow, 39). The halo is a refractive phenomenon, while rainbows and parhelia involve both reflection and refraction.

15 Sayili carefully considers (in the context of the rainbow) such a criticism in light of later understanding of the laws of reflection ('explanation of the rainbow', 80). 
In order to appreciate Aristotle's contribution to this account, it is useful to realize that not all of his successors comprehended the optical and observer-dependent aspect of such phenomena, nor did they appreciate the power of geometry to help explain the extraordinarily regular shape of the halo. ${ }^{16}$ Compare, for example, Epicurus' explanation of the same phenomenon.

The halo around the moon is produced because air from all sides moves towards the moon; or when it evenly restricts [the movement of] the effluences sent off from it to such an extent that this cloudlike phenomenon forms around it in a circle and is not interrupted in the slightest extent; or it restricts [the movement of] the air around it symmetrically on all sides so that what is around it takes on a round and dense formation. And this happens in certain parts either because a certain effluence forces its way from outside or because heat occupies passages suitable for the production of this effect. ${ }^{17}$

Seneca's explanation is more detailed, but along these same lines.

When air is compressed it can react to a blow; the light of the sun or of the moon, or of any star, encountering it forces it to recede in circles. Moisture and air, and in fact anything which is shaped by a blow, is forced into the same shape as that which shaped it. Now all light is round. Therefore, air also struck by light will go in this round formation. $^{18}$

16 And it is still not being understood today. I recently came across an article written by a science journalist for Reuters, on solar winds. The article contained an irrelevant picture of a solar halo with the caption: 'a halo, an optical phenomenon caused by rare atmospheric conditions that appear around the sun, is photographed in Medan in Indonesia's North Sumatra province earlier this week; new data from the Ulysses spacecraft shows that solar winds are at their lowest in the past 50 years' (S. Gorman, 'New data shows less blustery sun': Reuters 2008, September 2008, from The Vancouver Province).

17 Pyth 110-11, trans. B. Inwood, in The Epicurus Reader (Indianapolis: Hackett 1994), 26. Lucretius does not discuss the halo in DRN VI.

18 NQ I 2.2, tr. T. H. Corcoran, Seneca: Naturales Quaestiones, vol. 1 (Cambridge, MA: Harvard University Press 1971). The discussion of the halo is at I 2.1-11; cf. I 10.1. 
Epicurus' and Seneca's explanations revert to the traditional cloud-formation account found in Xenophanes and Anaximines and do not take notice of Aristotle's geometrical-optical account of the same phenomenon. Nor do they mention Anaxagoras' account, although we have so little evidence of his view that one should not press the point. Epicurus does not show any awareness of Aristotle's explanation, or any interest in trying to geometrize the problem, in spite of the fact that his approach to meteorological explanations usually encourages him to canvass as many as are plausible; although perhaps Aristotle's solution would not be consistent with Epicurean physics and canonic. We are talking about an optical illusion here, a frequent objection to Epicurean canonic, and even if Epicurus were aware of the geometrical-optical explanation, he might be compelled by his staunch realism to offer a more traditional atomistic explanation. More specifically, the theory of vision according to which simulacra are directly received by the eyes is not well suited to explain phenomena of diffused reflection, that is, reflection in which there is no recognizable translation of the shape of the original object. ${ }^{19}$ Nor does Seneca discuss the optical illusion explanation of the halo, even though elsewhere in his work he uses Aristotle's Meteorology, and he is aware of the difference between substantial and reflective phenomena and employs it in his explanation of the rainbow. ${ }^{20}$

Aristotle's explanation or some later peripatetic version of it is used by Aëtius and by extension the author of the epitome of natural philosophy attributed to Pseudo-Plutarch.

19 I thank the anonymous reader for this suggestion. Although Lucretius does not discuss the halo, the discussion of mirrors at DRN IV 269-323 supports the suggestion because the Epicurean is shown there struggling to analogize reflection in a mirror to the direct transmission of images as seen for example through a doorway. Lucretius' discussion of mirrors immediately precedes the discussion of problems of vision (324-78), optical illusions (379-468), and an attempt to refute the objections based on the fallibility of the senses and the dire skeptical implications for a theory of knowledge based on the senses (469-521).

20 NQ 1.15.6. See J. Mansfeld, 'From Milky Way to Halo', in A. Brancacci, ed., Philosophy and Doxography in the Imperial Age (Firenze: Leo S. Olschki Editore 2005) 23-58. Mansfeld's article is important and illuminating, but he fails to notice this difference in Seneca's accounts of the halo and the rainbow when he states that, 'As to the distinction between reality and appearance in general, Seneca states near the end of the next Book (our Book I) that no one doubts that meteors etc. are real, whereas it is a matter of discussion whether or not the rainbow and the halo are real or not. His own opinion is that the rainbow and the halo are deceptive optical phenomena' (40-1). 
The halo is formed in this way. Between the moon (or some other star) and our sight stands thick and misty air. Now when in this [air]

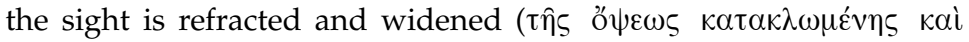

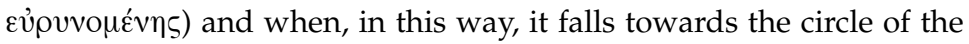
star, a circle seems to appear around the star in the region of its outer circumference; the apparition seems to come about whenever this af-

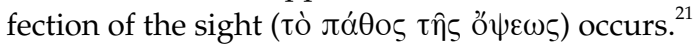

Although this account is sketchy, presents its own problems, and oddly is not attributed to any particular philosopher, it goes beyond the air-modification theory and treats the halo as an optical phenomenon. Aëtius, the source for the author of the Epitome, was one of the latest ancient writers to discuss the rainbow and halo in any detail. ${ }^{22}$ His report about the halo is evidently dependent on Aristotle's Meteorology,

21 [Plutarch], Epitome 897d1-8 = Aetius III.18 = Diels DG, 384). After the words 'its outer circumference' the text reads 'which circle is apparently called "halo" because it is akin to a halo [= threshing area]'. Diels put this etymological argument in brackets because the passage makes much more grammatical sense without it, and is probably an irrelevant interpolation. The same point is also made by Seneca: 'For this reason the Greeks call such shining lights "threshing-floors" (areas) because generally the places set aside for threshing grain are round' (NQ 1.2.3, tr. Corcoran). Aristotle uses the term 'halo' this way in the famous rainfall argument of $P h$ II 8 at 198b22. The argument there is about how the farmer might leave the grain out 'in the halo' ( $\dot{\varepsilon} \vee$ ๆ 33 Aristotle points out that the meteorological halo is an indication of rain, and so if a farmer was to leave his grain exposed in the event of a halo, it might very well be ruined by rain. The author of De Signis also discusses the halo as a sign of impending rain (and wind), Sign 22.152, 31.219, 51.372; see also the comments of D. Sider, Theophrastus of Eresus: On Weather Signs (Leiden: Brill 2007), 144-5.

22 If it is right to read $\kappa \alpha \tau \alpha \kappa \lambda \omega \mu \varepsilon \dot{v} \eta \varsigma$ as a reference to refraction, this may represent an important advance on Aristotle's theory (since Aristotle does not distinguish between reflection and refraction). See also Alexander of Aphrodisias' commentary on the Meteorology, ad loc. Alexander notes that Posidonius agreed with Aristotle's explanation, but that unnamed others attributed the halo to refraction of rays as opposed to reflection (Alexandri in Aristotelis Meteorologicorum libros commentaria $=$ CIAG vol. 3. par. 2, M. Hayduck, ed. [Berlin: Reimeri 1899], 143.7-12). This would, again, suggest an ancient advance on Aristotle, but Alexander summarily rejects their solution, and the stream of evidence positively characterizing the view runs dry. The story picks up again as early as Robert Grossteste (C. B. Bower, 'Refraction and the Rainbow in Antiquity', Isis 47 [1956], 383-386). Still, Alexander's concern to defend the reflection theory indicates the presence of opposing views in antiquity. 
as Jaap Mansfeld has recently demonstrated. ${ }^{23}$ This can be further substantiated by a close examination of Aristotle's explanation of the halo in Meteorology III, to which we now turn.

Aristotle's account of the halo begins in Meteorology III 2, where he treats it as a species of optical-meteorological phenomena.

And we should speak about the halo and the rainbow, both what

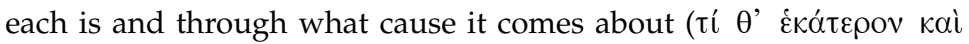

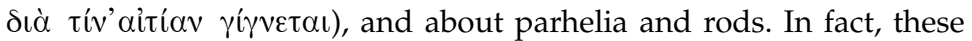
come about - all of them - through the same causes, which are the same for one another. But first we must get the affections and the at-

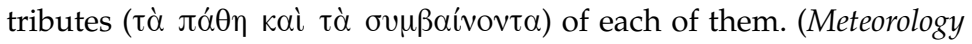
III 2, 371b18-22)

This passage represents a clear methodology: first describe the facts ('what each is'; 'the affections and attributes'), and then at a later stage give the reason why these are the facts ('through what cause'). This is the procedure Aristotle recommends in the methodological preface of Parts of Animals I 1, a procedure he attributes to 'the mathematicians in their astronomical expositions', according to which 'the naturalist must observe the phenomena of animals and the parts of each of them first, after this proceeding to discuss the reason and the cause' $(639 \mathrm{~b} 7-10){ }^{24}{ }^{2}$

Further, this is precisely the methodology that Aristotle recommends for the investigation of optical phenomena in Posterior Analytics $\mathrm{I} 13,{ }^{25}$ although in that work he suggests that one science will give the

23 'The halo is explained as being caused by the refraction, i.e. a sort of reflection, of our visual rays towards the moon or another heavenly body... this is a version of Aristotle's explanation of the halo as a purely optical phenomenon, meteoro$\log$. 372b12-373a31, for Theophrastus' explanation, fortunately extant, is different' ('From Milky Way to Halo', 47-8).

24 Cf. HA I 6, 491a10-13; PA II 1, 646a8-12; IA 1, 704b8-11.

25 See also de An I 1, 402a16-22 where the method seems to be mentioned in a general context. 
description of the facts but a different science will give the explanation of the reason why. ${ }^{26}$

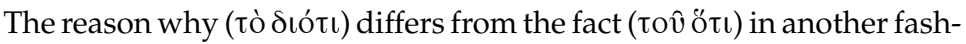
ion, when each is considered by means of a different science. And such are those sciences related to each other in such a way that the one is under the other, e.g. optics to geometry, and mechanics to stereometry, and harmonics to arithmetic, and star-gazing ( $\tau \grave{\alpha} \phi \alpha \iota v o ́ \mu \varepsilon v \alpha$ ) to astronomy.

Some of these sciences bear almost the same name, e.g., mathematical and nautical astronomy, and mathematical and acoustical harmonics. Here it is for the empirical scientists to know the fact ( $\tau$ ò $\mu \dot{\varepsilon} v$ ö $\tau$ ) and for the mathematical scientists to know the reason why ( $\tau$ ò $\delta \dot{\varepsilon} \delta ı$ tı); for the latter have the demonstrations of the causes

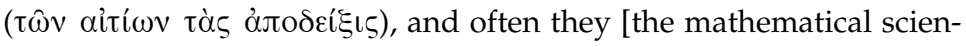
tists] do not know the fact, just as those who study universals often do not know some of the particulars through lack of observation.

The items in question are things which, being something different in theiressence,makeuseofforms. Formathematicsisconcerned withforms, for its objects are not said of [i.e., 'predicated of'] any underlying subject - for even if geometrical objects are said of some underlying subject, still it is not as being said of an underlying subject that they are studied.

Related to optics as this is related to geometry, there is another science, that of the iris. Here it is for the natural scientists to know the fact [about the iris], and for the students of optics (either of optics simpliciter or of mathematical optics) to know the reason why. (Posterior Analytics I 13, 78b34-79a13)

In general, Aristotle prohibits or at least resists explaining the phenomena in one domain by reference to the theorems or principles appropriate to another domain. ${ }^{27}$ But in Posterior Analytics I 7, he suggests that the theorems of one science may be demonstrated by the propositions

26 My translations of the Posterior Analytics are based on those of J. Barnes in both the Revised Oxford Translation (a 'lightly revised' version of the first edition of his Clarendon translation) and the second edition of his Clarendon translation, Aristotle: Posterior Analytics (Oxford: Oxford University Press 1993). I have introduced modifications only for the sake of consistency with other passages. His note on the present passage (158-62) is an invaluable summary of the issues surrounding subalternation, including difficulties and related passages.

27 Hankinson, 'Kind-Crossing', 28-37 
of another science, but only in the event that one science is 'under the

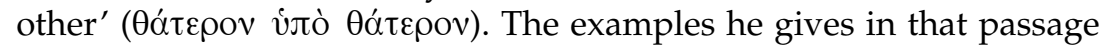
are: geometry and optics; arithmetic and harmonics; stereometry and mechanics; and astronomy and 'star-gazing'. ${ }^{28}$

It is important that these relations be specified: Aristotle rejects the possibility of a single super-science to which everything else is subordinated and that could potentially explain everything. ${ }^{29}$ Only some sciences are subalternate to some others, and for example not every scientific theorem will be demonstrated with reference to geometrical propositions, 'but only those from which either there is shown

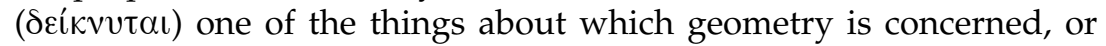
something which is shown from the same things as geometry, such as optical things' (Posterior Analytics I 12, 77a41-b2).

It will be noticed that, in 78b39-79a6, Aristotle makes a further distinction between an empirical and an explanatory-mathematical version of some of the subalternate sciences, distinguishing for example between 'nautical' and 'mathematical' astronomy, and between 'acoustical' and 'mathematical' harmonics. Nautical astronomy and acoustical harmonics are apparently empirical sciences concerned with establishing the facts ( $\tau$ ò ö $\tau \iota$ ) about the stars and about sounds and music to be explained, while mathematical astronomy and harmonics

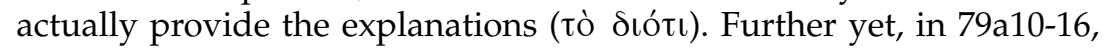
Aristotle suggests the possibility of a third science being subalternate to the already subalternate science of optics. In that case we evidently have a triadic hierarchy. Perhaps the preceding examples can be used to illustrate this: arithmetic and mathematical harmonics and acoustical harmonics; ${ }^{30}$ or stereometry and mathematical astronomy and nautical astronomy. Along the same lines we could expect that the explanation of the rudder will require the theorems of mechanics, a science which will itself depend on the principles of stereometry, which suggests the following subalternation: stereometry and mechanics and the science of the rudder. More to the point of the present investigation, consider

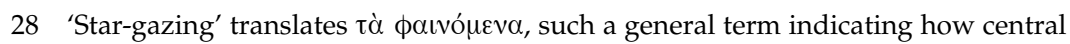
astronomy was to scientific theorizing around the time of the Analytics. For difficulties with the specific examples, see Barnes, Posterior Analytics, 158-62; Lennox, 'Mixed Sciences', 43-9; Hankinson, 'Kind-Crossing', 38-9.

29 Hankinson, 'Kind-Crossing', 40-3

30 See McKirahan, 'Subordinate Sciences', 206-10 for an interesting discussion of the distinction between acoustical and mathematical harmonics. 
the following subalternation: geometry and optics and iridology. In this arrangement, the explanation of Iris-phenomena depends on the theorems of optics, which in turn depend on the principles of geometry. ${ }^{31} \mathrm{As}$ I will argue, something like a triadic hierarchy seems to be Aristotle's conception, although there is just enough ambiguity in his expression to prevent a definitive resolution of the issue. ${ }^{32}$

Despite complications with the details, however, the division of labor discussed in Posterior Analytics I 13 is fairly clear: it is between an explanatory science (harmonics, astronomy, optics, mechanics) that provides the causes or explanation for these facts ( $\tau$ ì $\delta ı$ ' $\tau$ ), and an empirical science that collects data or the fact ( $\tau$ ò ö $\tau$, e.g. facts about sounds and music, about the planets, about halos or parhelia, about levers and rudders, etc.). On the triadic structure, the lowest science remains the empirical one providing tò ötı (e.g., iridology or, more generally, meteorological optics), but two super-ordinate sciences (e.g.,

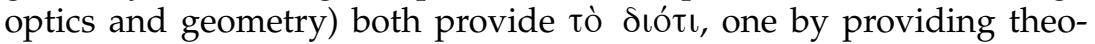
rems, and the other in providing the ultimate tò dıótı in the form of an axiom or definition (more on this below). ${ }^{33}$

The fact that the natural scientist of the Meteorology is at the same time a mathematician should come as no surprise. For, as we are told in

31 Following the classic interpretation of Ross: 'The first science discovers certain very general laws about numbers, plane figures, or solids. The third, which is only by courtesy called a science, collects certain empirical facts. The second, borrowing its major premises from the first and its minor premises from the third, explain facts which the third discovers without explaining them. Cf. Heath, Mathematics in Aristotle, 58-61' (W.D. Ross, Aristotle: Prior and Posterior Analytics [Oxford: Oxford University Press, 1949], 555).

32 Some of the difficulties with the triadic arrangement are discussed by McKirahan, 'Subordinate Sciences', 213-15. Lennox, 'Mixed Sciences', 42-4, proposes a non-triadic interpretation. Hankinson, after a complete survey of the relevant texts, notes that even if Aristotle refers to a bipartite structure in two different ways, 'there seems to be no reason why... Aristotle could not have supposed such a threefold structure to hold' ('Kind-Crossing', 48n77).

33 In non-subalternation cases these will all be concerns of the same science. Thus Aristotle suggests that every science is concerned with three things in Posterior Analytics I 10: 'Every demonstrative science is concerned with three things: what it posits to exist (these items constitute the kind of which it studies the attributes which hold of it in itself); the so-called common axioms, i.e. the primitives from which its demonstrations proceed; and thirdly the attributes, where it assumes what each of them means' (I 10, 76b11-16; cf. I 7, 75a38-b6). See also Hankinson, 'Kind-Crossing', 41-2. 
the Physics: 'the more physical of the mathematical sciences' (the examples given are optics, astronomy, and harmonics) deal with the physical aspects of mathematical objects insofar as they are physical, while the mathematician deals with the mathematical aspects of physical objects: 'while geometry investigates natural lines but not insofar as they are natural, optics investigates mathematical lines, but insofar as they are natural, not mathematical' (II 2, 194a9-12, tr. Ross). Thus the natural scientist describes the halo as a reflection of visual rays in the shape of a circle. The mathematician should explain why it is a circle, according to mathematical, not physical, principles.

The reason the mathematician is able to do this is that the circle has the same essential geometrical properties whether it is made of bronze, sand, or light. Thus the fact that the halo is made of light is not essential to the ultimate explanation of its being a circle; the explanation will have to do with the necessary properties of circles, not of air or water or light. ${ }^{34}$ Thus Aristotle treats the science of the halo as a doubly subalternate science, insofar as he treats the halo as a phenomenon to be explained by optics, but this is understood to be a science that in turn that gets its principles from the superordinate science of geometry. In effect, the halo phenomenon is abstracted from all physical considerations like the nature of light, the matter of the optical rays, or the physiology of perception; halos and rainbows are ultimately treated as geometrical objects like circles and cones. ${ }^{35}$

34 Heath, Mathematics, 60. As Lennox explains, in the 'mixed sciences' the 'explananda attribute mathematical properties to physical objects, but not qua the sorts of (mathematical) things that must have those properties. That some mathematical property belongs to some natural object may be necessarily true, but not because of the physical nature of that body. The middle term picks out the description of the natural object in virtue of which it has a certain mathematical property; that property is a per se property of a natural kind qua being a mathematical kind' ('Mixed sciences', 41). On this issue, see now the interesting work in progress by Reviel Netz, 'Aristotle's Metaphysics M3: Realism and the philosophy of QUA', Princeton/Stanford Working Papers in Philosophy, ver. 1.0 (2006), 1-38.

35 McKirahan describes Euclid's method of optics as essentially geometrical, making 'no reference to any psychological or physical considerations... in making abstraction of all purely qualitative and physical aspects of vision such as light and color, Euclid and his predecessors could restrict the field of optics to what interested them, and in particular to what they were especially well-equipped to treat: a theory of the visual perception of space...there was no need or possibility of mental elaboration which would give it psychological significance in addition to the fact that it can be represented geometrically' ('Subordinate Sciences', 199). I think that 
In this way the methodology recommended in Posterior Analytics I 13 is followed in Meteorology III 2-3. So we may suppose that the first stage of the explanatory process will be to describe the meteorological phenomena of halos, and then explain them according to the theorems of optics and the principles of geometry. The first part of this process, the description of the phenomenon, is achieved in Meteorology III 2, and later in III 3 an optical-geometrical explanation for this is given. Here is the description of the facts.

The complete circle ( $\kappa$ $\kappa \lambda \circ \varsigma$ ö $\lambda \circ \varsigma$ ) of the halo appears often, and comes about around the sun and moon, and also around the luminous ones of the stars; ${ }^{36}$ and, furthermore, it does so no less at night than in the daytime (that is, around midday and the afternoon, for it appears less frequently at dawn and twilight). (Meteorology III 2, 371b22-25)

There are at least two facts here to be explained: (1) why the halo always comes to be around a luminous object, such as the moon (and not opposite it, as for example with the rainbow); and (2) why the halo always comes to be a complete circle. After describing the halo, Aristotle describes the phenomena of the rainbow, parhelia, and 'rods' (i.e., arcs). Interestingly, Aristotle indicates that he has personally made some observations; for example he says that he has only observed a lunar rainbow twice in over fifty years (372a26-9) ${ }^{37}$ Following the descriptions, he asserts that the cause of all these Iris-halo phenomena is the same, and he also says on what basis they are differentiated.

the case of the halo and other geometrical-optical-meteorological phenomena support McKirahan's position and show that Aristotle should be counted among the 'predecessors' of Euclid mentioned here.

36 It is surprising to see this claim, as the $22^{\circ}$ halo is not seen around even bright stars; coronae, on the other hand are, and this is one reason to think that Aristotle could have been describing what we call coronae and not what we call a halo. (This intriguing suggestion was made to me by Les Cowley in a personal communication.)

37 It is also interesting that Aristotle points out that 'the ancients thought it did not come about at night by the moon' (372a21-2); see above note 11 on Anaximenes, who does assert that the rainbow appears at night. Another interesting report is about parhelia seen in Bosporus (372a13-15), although it is not clear whether this is a direct observation made by Aristotle himself, or an indirect report. 
Now then, these are the attributes of each of them [rainbows, halos, mock suns, 'rods']. But the cause of all of them is the same. For these are all a reflection ( $\dot{\alpha} v \alpha \dot{k} \lambda \alpha \sigma \iota \varsigma)$. But they differ in the ways [they reflect] and the things from which [they reflect] and how the reflection happens to come about with respect to the sun or to any other of the luminous objects. (Meteorology III 2, 372a16-21)

So reflection is the cause of all these phenomena, and they are differentiated from one another by the manner of the reflection (i.e., the relative positions of the bright object and the observer), and the smoothness of the reflective surface. As for the nature of reflection itself, and thus the basis of differentiating iris-halo phenomena, Aristotle borrows his position from the science of optics.

Now then, that sight is reflected ( $\dot{\eta}$ ö $\psi \iota \varsigma \grave{\alpha} v \alpha \kappa \lambda \hat{\alpha} \tau \alpha \iota)$, just as from water, so too from air and from all of the things having a smooth surface, we must take confidence from the expositions of optics ( $\dot{\varepsilon} \kappa \tau \hat{\omega} \nu \pi \varepsilon \rho i$

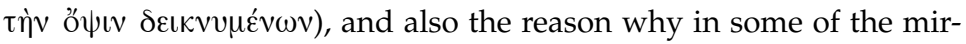
rors even the shapes are manifested, but in others only the colors are. (Meteorology III 2, 372a29-34)

The distinction between two kinds of reflection serves to divide opticalmeteorological phenomena into two species: those in which color only is reflected (e.g. rainbows and halos) and those in which both color and shape are reflected (e.g., looking glass mirrors). Aristotle does not in any extant work offer an extended explanation of reflection in his latter sense, and his assumption that reflection is the cause in the case of both the halo and the rainbow makes him fail to appreciate that the cause in the case of the halo phenomena is refraction (and is diffraction in the case of coronae), not reflection. His failure in this regard has been plausibly attributed to his macroscopic focus on the meteorological sphere instead of a microscopic analysis of the exact nature of the illuminated surfaces in the cloud that is the substratum for halo phenomena. ${ }^{38}$

But this understandable failure was not due to blind adherence to doctrine, because Aristotle is here flexible enough to adopt a theory of vision explicitly rejected in his psychological works, for the purposes

38 Modern atmospheric optics does not recognize Aristotle's distinction between these two kinds of reflection, and it had no positive effect on the explanation of the rainbow (Boyer, The Rainbow, 39 and 54). 
of better explaining the halo phenomenon. It was pointed out by Galen and Alexander (in his commentary on the halo passage) that the theory of vision assumed here does not jibe with the theory of vision presented in the de Anima (and assumed elsewhere), according to which light is a modification of a transparent medium (de Anima II 7; cf. de Sensu 3). ${ }^{39}$ However that may be, in the Meteorology Aristotle uses the theory of visual rays, according to which 'sight' (ő $\psi \iota \varsigma$ ), in the form of a visual ray, instantaneously extends from the eye to the visible object. The reason Aristotle adopted the visual ray theory in the Meteorology is apparently that this theory will allow him to make use of geometrical demonstrations via the subalternation of optics to geometry. It would seem that Aristotle was here following the lead of Archytas of Terentum, who advanced the theory of the optical ray, and most likely did so for the sake of permitting geometrical explanations of optical phenomena. ${ }^{40}$

Such demonstrations are apparently not possible or at least not very easy on the supposition that images are directly transmitted to the eye, or that light is a modification of a medium; such theories of vision have difficulty explaining why a perfect figure should reappear but is not the image of any substantial object. Just as the Epicurean theory of vision (according to which simulacra are directly received by the sense organ) evidently has difficulty explaining phenomena of diffused reflection, so does the Aristotelian theory which presupposes that images

39 Aristotle rejects such a theory that he finds in Empedocles (Sens 2 373b34-374a4). See Galen, de plac Hipp et Plat 7.7.10f; Alexander, in Meteor 141.3-142.20. See also D. Lehoux, 'Observers, Objects, and the Embedded Eye', Isis 98 (2007) 447-67, at 452-3; Mansfeld, 'From Milky Way to Halo', 24.

40 See fragment A25 (texts A, B, and C) in Archytas of Tarentum: Pythagorean, Philosopher and Mathematician King by C. Huffmann (Cambridge: Cambridge University Press 2005), with the extensive and very helpful commentary, 551-69. Early versions of the theory according to which images come to the eyes from outside were adopted by Empedocles, Leucippus, Democritus, and later the Epicureans. The opposing theory of visual rays was utilized by Archytas, Plato and later the Stoics (their views differ in the details of the propagation of the rays). Archytas does not specifically mention optics as a subalternate science (one is especially surprised to see it not mentioned in his fragment 1 ), although there is ample evidence that he recognized mathematical optics as a science (see Huffman, 559). The absence of a reference to optics in the Republic but presence in the Posterior Analytics suggests that someone has developed a mathematical treatment of optics in the meantime, and that someone is most likely to have been Archytas, as M. Burnyeat has persuasively argued ('Archytas and Optics', Science in Context 18 [2005] 35-53). 
are transmitted as forms directly through a transparent medium. ${ }^{41}$ The geometrical explanation, on the other hand, requires no reference to the medium or to the shape of the source of illumination, but only definite lines that connect the sense organ and the illuminated object, and represent the uniform angle of 'reflection' at the circular figure of the halo; and the theory of visual rays conveniently provides such instruments. Similarly, Euclid employed the theory of visual rays because, as McKirahan points out, it is 'a device which has a certain success in accounting for geometrical aspects of visual representation. ${ }^{42}$ Aristotle set the pattern for later developments in optics by using the theory of visual rays instrumentally without trying to prove it as a matter of physiological or psychological fact. Thus, after making some more points about reflection and color relevant to the explanation of the rainbow, he reiterates:

But about these things there has been theorization by us in the expositions con-

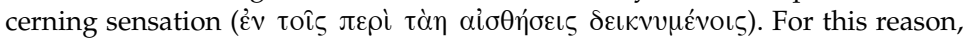
some things we are discussing, while other things we are using by assuming their existence. (Meteorology III 2, 372b9-11)

In the last two inset passages quoted, does Aristotle refer to one science

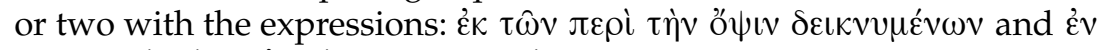

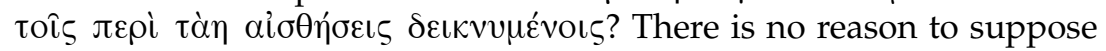
that Aristotle here intends us to understand optics as well as some other separate science of perception, perhaps a psycho-physiological treatment of vision like in de Sensu 3 (as has been suggested in some notes to this passage). All that Aristotle seems to mean here is the kind of arrangement he discusses in Posterior Analytics I 13, 79a10-13 between a mathematical and an empirical science. For after the identification of the facts about the halo (etc.), he says that we must appeal to the science of optics for theorems about the nature of reflective surfaces and the nature of vision. These theorems in turn depend on the principles

41 According to D. C. Lindberg, Theories of Vision from al-Kindi to Kepler (Chicago: University of Chicago Press 1976), 217n39, Aristotle adopted the visual ray theory early in his career only to reject it later in the psychological works. The chronological point is not important to the present argument, but it is interesting to think that Aristotle in the Meteorology may have been under the influence of Archytan or Pythagorean ideas, which he presumably learned in the Academy.

42 McKirahan, 'Subordinate', 199; see further: P. Lettinick, Aristotle's Meteorology and its Reception in the Arab World (Leiden: Brill 1999), 245. 
of geometry, and hence allow for a connection between the physical phenomena and the mathematical explanation.

The genus of reflected phenomena are all caused, then, by the reflection of the visual ray, against the smooth surfaces of raindrops and mist formed when air and vapor condense into clouds (372b15-17). These clouds act as mirrors of bright objects such as the sun. It remains to be shown why it is that halos, unlike rainbows, parhelia, and rods, are always perfectly round, forming a 'whole circle'. We have been prepared for an optical explanation appealing to the principles of geometry.

\section{III}

In Meteorology III 3, Aristotle undertakes to explain phenomena of the halo specifically.

But first we should speak about the shape of the halo, both the reason

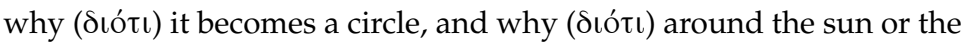
moon (and similarly as well around any of the other stars). For the same account agrees in all these cases. Now then, the reflection of the sight comes about in this way when the air and vapor condense into a cloud, if the vapor, which has been condensed, happens to be uniform

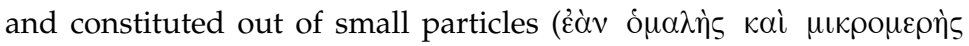

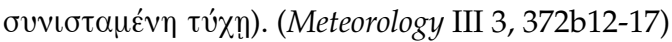

We are told that halos themselves are a meteorological kind with several species: lunar, solar, stellar, etc. Again, Aristotle may be referring either to the $22^{\circ}$ halo, the $46^{\circ}$ halo, or coronae. But all of these are said by Aristotle to have the same cause: the 'reflection' of light to the observer from a cloud of condensed air and vapor. The air and vapor is said to be uniform and the particles are said to be small. (In fact, the cloud causing the halos consists of ice crystals of plate, column, and pyramidal habit ranging in size from $40 \mu \mathrm{m}$ to $1 \mathrm{~mm}$. The crystals causing the $22^{\circ}$ halo are uniformly the column-type with diameters less than $20 \mu \mathrm{m} .{ }^{43}$ ) Aristotle's specification of the reflecting medium relates to one of the two kinds of differentia mentioned above. In a later passage, Aristotle mentions the

43 The definitive account of this, along with photographic illustrations of the crystals, is: W. Tape, Atmospheric Halos, Antarctic Research Series, Vol. 64 (Washington, DC: American Geophysical Union 1994). 
other kind of difference (the relative positions of the observer and the bright object). In the process he offers his explanation.

Now then, it has been said how the reflection comes about given a certain condition of the air. The sight is reflected from the mist that condenses around the sun or the moon. This is why it does not appear opposite [the sun or the moon] as does the rainbow.

And since the sight is reflected similarly from all directions, the result is necessarily a circle or part of a circle. For when lines from the same point and to the same point are equal, the points forming an angle always lie on a circle. (Meteorology III 3, 372b33-3a5)

This account addresses both of the phenomena of the halo identified in Meteorology III 2. So the reason that a halo always forms around a luminous body (and not, for example, opposite it, as with the rainbow) is that it is a reflection of the 'sight' on a cloud of minute condensed particles suspended in the air between the observer and the luminous body, e.g., the moon. And the reason the halo is always a circle is that the optical rays are all reflected from the cloud at exactly the same angle. But if the reflection is always at the same angle, because the particles are uniform, then the result will be a circle. (This is $22^{\circ}$ because of the refractive and prismatic effect of the hexagonal ice crystals in the cloud, and hence the modern name for the $22^{\circ}$ halo; more on this below.)

In order to appreciate that this is a bona fide explanation, it is necessary to observe some general points about scientific explanation according to Aristotle. In Posterior Analytics II 11, Aristotle says that 'we think we understand something when we know the explanation (or cause) (94a20). The most scientific explanations take the form of a first figure syllogism in Barbara whose middle term indicates one of four kinds of cause. There are four ways of explaining things or, to put it only slightly differently, four kinds of causes. But all of them, he says,

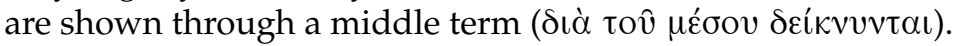

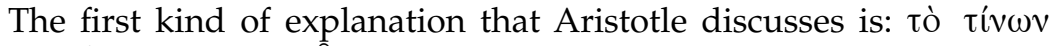

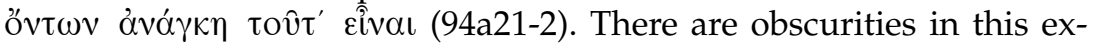
pression, and it literally means something like 'the [cause according to which] things being [true] necessitate that this is [true]'. Aristotle elaborates on this kind of explanation as follows.

The case in which if something holds it is necessary that this does, does not occur if one proposition is assumed, but only if at least two are; and this occurs when they have one middle term. So when this 
one thing [i.e. a single middle term] is assumed, it is necessary for the conclusion to hold.

It is clear too as follows. What is the reason ( $\delta\llcorner\alpha \dot{\alpha}$ ) that the angle in the semicircle is right? What is it that holds when the angle is right? Well, let right be $A$; half of two rights $B$; the angle in the semicircle $C$. Thus $B$ is the explanation of why A, right, belongs to $C$, the angle in the semicircle $C$. Thus $B$ is the explanation of why $A$, right, belongs to $\mathrm{C}$, the angle in the semicircle. For this is equal to A and $\mathrm{C}$ to $\mathrm{B}$; for it is half of two rights. So if $\mathrm{B}$, half of two rights, holds, then A belongs to $C$ (that is, the angle in the semicircle is right). And what it is to be it [i.e. its definition or essence, $\tau \hat{i} \hat{\eta} v$ Eiv $\alpha \iota)$ is the same as this, since

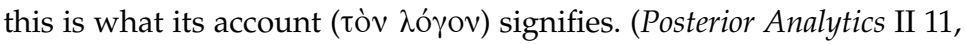
94a24-35)

As pointed out by J. A. Novak, the syllogism that Aristotle has in mind is straightforwardly a first figure syllogism in Barbara. ${ }^{44}$

1. Right angle of every half of two right angles;

2. Half of two right angles of every angle in a semicircle;

3. Right angle of every angle in a semicircle.

On the other hand, there has been controversy over what 'proof' Aristotle has in mind here. Aristotle makes another reference to the necessary right angularity of every angle in a semicircle at Metaphysics IX 9, 1051a24-29. Ross and Heath both attempted to construe the geometrical argument in such a way that it would apply to both the Posterior Analytics II 11 and Metaphysics IX 9 passages. As Novak showed, their construal is inadequate for various reasons. In particular, 'Ross is unable to explain Aristotle's remark that B ("the half of two right angles") is identical with A ("a right angle") and notes that Aristotle "seems to contemplate some such definition of the rightness of the angle in a semicircle as 'its being right in consequence of being the half of two right angles' "; and for this little can be said' ${ }^{45}$ Heath in a later publication went on to offer a different construal for the Posterior Analytics passage, which Novak again shows to be an inadequate solution.

44 'A geometrical syllogism: Posterior Analytics II, 11', Apeiron 12 (1978) 26-33, at 27

45 'A geometrical syllogism', 29; cf. Ross, Aristotle's Prior and Posterior Analytics, 641. 
I will not review the details of this dispute because a convincing solution is available, as Novak showed. He argues that the kind of proof Aristotle has in mind is the same as that found in Euclid's Elements III 31. This is the suggestion of an anonymous scholar on the Metaphysics passage and a comment of Aquinas on the Posterior Analytics passage. ${ }^{46}$ Unlike the construal of Ross and Heath, this solution requires no additional theorem, and satisfies Aristotle's demand that the demonstration apply universally. But the major insight of Novak's article is to realize what this construal shows about Aristotle's method of explanation. As Novak points out, Aristotle frequently insists that the middle term in a demonstration is a definition, and this answers the question why ( $\delta$ เò $\tau i ́)$ one thing is attributed to another. ${ }^{47}$ The passage from Posterior Analytics ends with the remark: 'So if B, half of two rights, holds, then A belongs to $C$ (that is, the angle in the semicircle is right). And what it is to be it ( $\tau^{\prime} \hat{\eta} v$ Eivol) is the same as this, since this is what its account ( òv $\lambda$ ó $\gamma o v$ ) signifies'. At first glance the definition 'a right angle is the half of two right angles' seems to be 'a paradigm case of a useless circular definition'. But one should compare it closely with the definition of a right angle in Euclid ${ }^{48}$ : 'When a straight line set up on a straight line makes the adjacent angles equal to one another, each of the equal angles is right'. ${ }^{49}$

Thus Aristotle's explanation of the reason why the angle in the semicircle is always right, although at first appearing to beg the question and be a useless circular argument, actually appeals to a definition of a right angle as the middle term. If so, then it would be a legitimate explanatory move, or at least conform to his own stated methodology of explanation.

46 See 'A geometrical syllogism', 33n21 for details and references.

47 'A geometrical syllogism', 31; cf. Post An II 2 passim, and 91a6-32, 92a9-10, 93a30-3, 93b7-14.

48 It might not be entirely accurate to say that the elliptical definition 'one half of two right angles' is 'the exact technical meaning of a right angle as stated in Euclid's Elements Book I, definition 10' (Novak, 'A geometrical syllogism', 31), because Euclid does not assume in his definition that a straight line encompasses two right angles, rather he sets out to prove that (easily) at I 13.

49 Euclid, El I def.10, tr. T. L. Heath, Euclid: the thirteen books of the Elements, Volume 1, second ed (Cambridge: Cambridge University Press 1925) 
The suggestion is that something very similar to the explanation offered as a paradigm in Posterior Analytics II 11 is going on in the explanation of why the shape of the halo always forms a complete circle in Meteorology III 3. The key passage, from which the commentators hang their notes accusing Aristotle of confusion, emptiness or circularity, reads as follows: 'For when lines from the same point and to the same point are equal, the points forming an angle always lie on a circle' (373a4-5).

This has seemed to commentators like a paradigm case of begging the question, of providing an empty verbal equivalence instead of a reason. But it only takes a slight change in perspective to see that what Aristotle offers as a reason is a definition of the circle, which is exactly the kind of thing we should expect this kind of explanation to be.

As far as I know, there is no place in the corpus where Aristotle unambiguously defines the circle, but he sometimes comes close, as in the Rhetoric: 'that surface which extends equally from the middle every way' (III 6, 1407b27). The circle is also contrasted with a noncircle as follows: 'any other figure which does not have the lines from the middle equal, as for example an egg-shaped figure' (de Caelo II 4, 287a19). These expressions obviously relate to a presupposed definition of a circle (perhaps along the lines of the definition found in Euclid's Elements I, definition 15). Now if we allow that such definitions may constitute explanations when present as middle terms of a syllogism (as Aristotle asserts in Posterior Analytics II 11), then we can understand Aristotle's explanation of the circularity of the halo. The reason why the halo is circular is that the mirrors which happen to reflect sight to the star are at an equal angular distance from the observer. This part of the explanation of the circularity of the halo comes down to the definition of a circle, and in this way the definition could be the middle term of a syllogism in Barbara.

1. Circle of every figure formed by equal lines (etc.);

2. Figure formed by equal lines (etc.) of every halo;

3. Circle of every halo.

The principle of this explanation is the formal definition of a circle. As Lennox says generally of the mixed mathematical-physical sciences: 'the middle term picks out the description of the natural object in virtue of which it has a certain mathematical property; that property is a per se property of a natural kind qua being a mathematical kind'. To put it in the somewhat stilted causal-explanatory language of the Posterior 
Analytics, if a figure will be formed of equal lines and equal angles (etc.), then the result will necessarily be a circle; but the halo is a figure formed out of rays that happen to be reflected at equal angles in a cloud

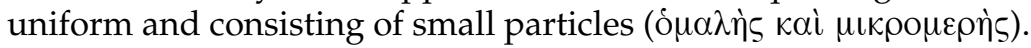

This appears to be a case then, frustratingly rare, in which Aristotle's pronounced method of explanation in the Posterior Analytics is executed in one of the scientific works, the Meteorology. ${ }^{50}$

\section{IV}

Aristotle's explanation of the fact that the halo always forms a complete circle is followed by a geometrical argument that is evidently meant to be accompanied by a diagram.

Let $\mathrm{ACB}$ and $\mathrm{AFB}$ and $\mathrm{ADB}$ be lines each of which goes from the point $A$ to the point $B$ and forms an angle. Let the lines $\mathrm{AC}, \mathrm{AF}, \mathrm{AD}$ be equal and those at $\mathrm{B}$ (viz. $\mathrm{CB}, \mathrm{FB}, \mathrm{DB})$ equal too. Draw the line $\mathrm{AEB}$. Then the triangles are equal; for their base AEB is equal. Draw perpendiculars to AEB from the angles; $\mathrm{CE}$ from C, FE from F, DE from D. Then these perpendiculars are equal, being in equal triangles and all in one plane; for they are all at right angles to AEB and meet at a single point E. So if you draw a line it will be a circle and $\mathrm{E}$ its center. Now B is the sun, A the eye, and the circumference passing through the points CFD the cloud from which the sight is reflected to the sun. (Meteorology III 3, 373a6-19, tr. Webster)

Figure 1 is a diagram of the construction included in a renaissance Latin translation of the works of Aristotle published in Venice in $1562 .^{51}$ No diagram survives in any manuscripts of the Meteorology (as far as I know, although I have not systematically checked this), but fortunately

50 This is of course not to say that syllogistic is an adequate framework for all geometrical proof, as it has been argued not to be by I. Mueller, 'Greek Mathematics and Greek Logic', in J. Corcoran, ed., Ancient Logic and Its Modern Interpretations (Dordrecht: D. Reidel 1974) 35-70.

51 M. A. Zimara, Aristotelis opera cum averrois commentariis, Volume V (Venice 1562; reprinted Frankfurt 1962), folio 449v 


\section{Meteorologicorum}

G Signum aût huius eft, $q$ hinc fit ventus, vndecūqs precipua fiat distractio . cùm vero marcefcit ferenitatis. fienim non difponit aliquałr fic aer, vt dñet́ calido, q đ intercipiť, neog veniat in in fpiffationç aquofam, palã eft nôdum vapor fegregat? eft $\mathbf{a b}$ exhalatione ficca, $\&$ ignea . hoc aūt ferenitatis elì cá. Q Qỉo igit $k$ habête aere fit refractio diçũ eft refrangitur aût à côfiftente caligine circa Solê, aut Lunā ví. fus.quapropter nô ex oppofito,

H ficut iris,apparet. Vndi'fs autem fitr refracto, neceffe eft circulū effe, aut circuli partem. ab eodê enim figno ad idem fignū xqua les frangentur fup circuli linea remp. Sit enim à puncto, in quo A, ad B fracta, \& ea, quę eft A C B, \& qux A F B, Q Q qux A D B.qqua les aũt $\mathcal{Q}$ h $x \wedge \mathrm{C}, \wedge F, \wedge D$ inuicé, $\mathcal{Q}$ qux ad B inuicê, icilicet $C$ B, $\boldsymbol{F}$ B, D B. \& protrahatur A E B. Quare triāguli æquales. etenim fuper $x q u a l e m$, qux eft A E B.

Ducantur autem perpendicula res ad $A E$ B ex angulis, à cquidem, qux eft $C$ E: ab F aût, qux eft $F E:$ a $D$ autem, qux eft $D E$. Equales itaog $h x$. in $x q u a l i b u s$ enim triāgulis, $\alpha$ in vno plano oês.ad rectum enim oês, ei, quxe A E B, \& ad vnū punctum E COpulantur. Circulus igit erit de fcripta, centrum autem E.Sit au tem B quidem Sol, $A$ autem vifus, quę autem eft circa $C$ F D cir cunferentia, nubes, à qua refran gitur vifus ad Solem.

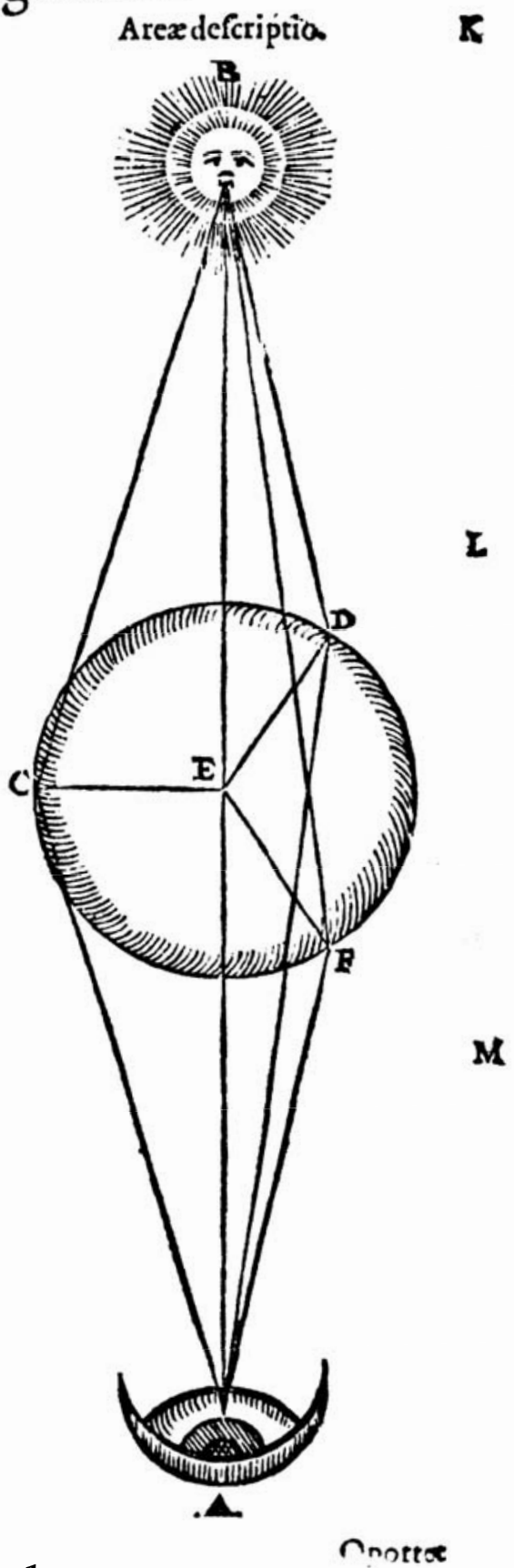

Figure 1 
it is not difficult to produce one that represents the essential aspects from these instructions. ${ }^{52}$

Reviel Netz, in his remarkably rich and insightful discussion of the use of diagrams in Greek mathematics, points out that this is one of the earliest uses of a lettered diagram in Greek science. ${ }^{53}$ That alone should be enough to secure its place in the history of the mathematization of natural science, and in particular of terrestrial science. But as a mathematical matter, Netz compares Archimedes' Method I with Aristotle's Meteorology III 3 to the disparagement of the latter: 'the one a masterpiece of deduction, the other hardly worthy of being called mathematics. ${ }^{54}$ His objection to Aristotle here is in the first case to the non-linear or 'fractal' presentation of the geometry: 'the proof of Aristotle's Meteorology passage is replete with deviant structures' (210), but also with the fact that Aristotle does not isolate the construction of the diagram from the proof:

In short: Aristotle does not compartmentalize, does not distinguish firmly between construction and proof, hence hiatuses, non-linearity, chaos. To develop the proof in an orderly fashion, it must be clearly separated from the construction. To co-operate, diagram and text must first be set apart. Indeed why should Aristotle compartmentalize his proof? After all, one thing that is clear about this proof is that it is not compartmentalized from a more general, non-mathematical discussion. The proof starts immediately from the discussion of the rainbow [sic], and ends, just as immediately, with an identification of the letters in the proof with the topics under discussion - eye, sun, cloud. The proof is embedded within a larger discursive context, and borrows the discursiveness from this context. (212)

There is much to agree with and admire in Netz' book, but also to disagree with in his treatment of this specific case. ${ }^{55}$ First, although the

52 As we find, for example, in the Oxford and Loeb translations (but not the Revised Oxford). See also: Boyer, The Rainbow, 63; Netz, The Shaping of Deduction in Greek Mathematics (Cambridge: Cambridge University Press 1999), 211; Taub, Ancient Meteorology, 111.

53 Shaping of Deduction, $45 \mathrm{n} 89$.

54 Shaping of Deduction, 210.

55 See also Taub, Ancient Meteorology, 113-15 for some further important considerations. 
diagram would be chaos if it were meant to accompany an explanation of the rainbow, in fact it is meant to accompany an explanation of an entirely different species of optical-meteorological phenomenon, the halo. Second, there is no reason to think that what Aristotle offers us is a 'proof' in the sense of Archimedes Method I. Aristotle is not trying to prove that the halo is a circle, but to explain why it always appears as

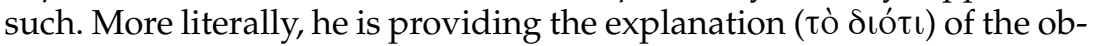
served fact ( $\tau$ ò ö $\tau$ ). According to Aristotle, the fact that the halo always appears as a circle is in fact not a matter for proof, but of observation. Aristotle asserted that the halo appears as a circle in a preliminary stage of describing the phenomenon. He then proceeds to explain why this is so (at least according to his own method of explanation). This is the discursive context of the diagram. And the diagram is still drawn for the same reason in modern textbooks on atmospheric optics (although with some important details added, see below).

The earliest extant version of the diagram that I know of is the one found in Alessandro Piccolomini's commentary on Alexander's Commentary on Aristotle's Meteorology, published in Venice in $1540 .^{56}$ The historian of the rainbow Carl B. Boyer was only half right in complaining that the 'diagram for the halo recurred with monotonous regularity in connection with later meteorological commentaries until the seventeenth century ${ }^{\prime 57}$ For the diagram did not stop being produced in the seventeenth century. Modified versions of it can be found in: (figure 2) M. Minnaert's The Nature of Light and Color in the Open Air $(1954,193)$; (figure 3) Robert Greenler's Rainbows, Halos, and Glories (1980, 26); more recently (figure 4) C. D. Ahrens' Meteorology Today (2000, 93); and the diagrams available on (figure 5) Les Cowley's web site 'Atmospheric Optics'. Now either the drawers of these diagrams have been directly or indirectly influenced by the drawing of Aristotle, or they have independently reproduced it; either way, the scientific value of Aristotle's diagram is beyond doubt.

The modern explanation of the phenomenon is that a $22^{\circ}$ halo can be seen when hexagonal columnar ice-crystals smaller than $20 \mu \mathrm{m}$ are suspended at random in the atmosphere between the observer and a

56 Alexandri Aphrodisiensis maximi peripatetici, in quator libros Meteorologicorum Aristotelis, commentario lucidissime, Alexandro Piccolomineo interprete (Venice 1548) f. 35v. The diagram is printed in Taub, Meteorology, 12.

57 The Rainbow, 64. See also, S. K. Heninger, A Handbook of Ranaissance Meteorology (Durham, NC: Duke University Press 1960), 138-9. 
352 Monte Ransome Johnson
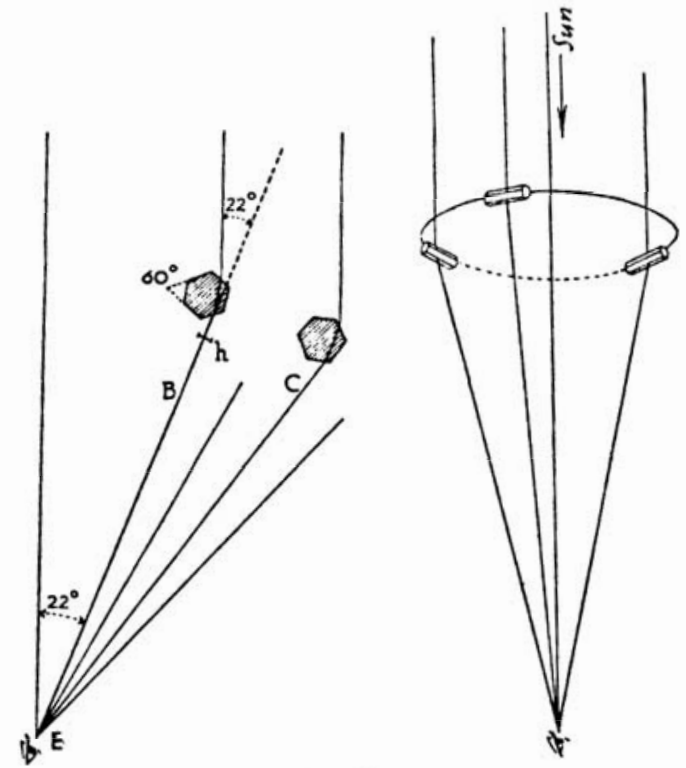

Fic. 122. How the 'small,' or ' $22^{\circ}$ halo' arises.

Figure 2

Ruinbous, balos, and glories

Figure 2-6. To set sunlight that is

deviated by an angle D, you look at an angle D away from the sun.

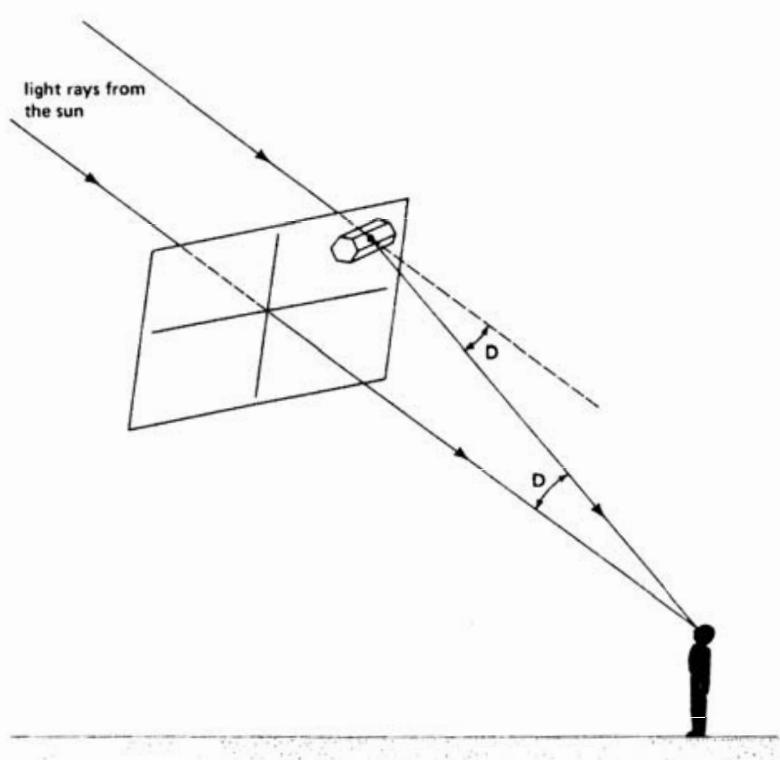

Figure 3 


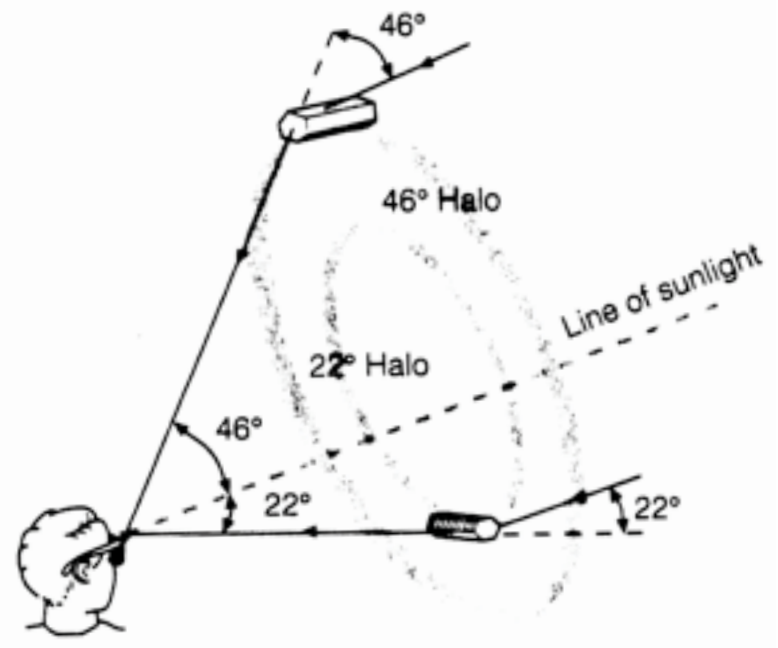

FIGURE 4.19

The formation of a $22^{\circ}$ and a $46^{\circ}$ halo.

Figure 4

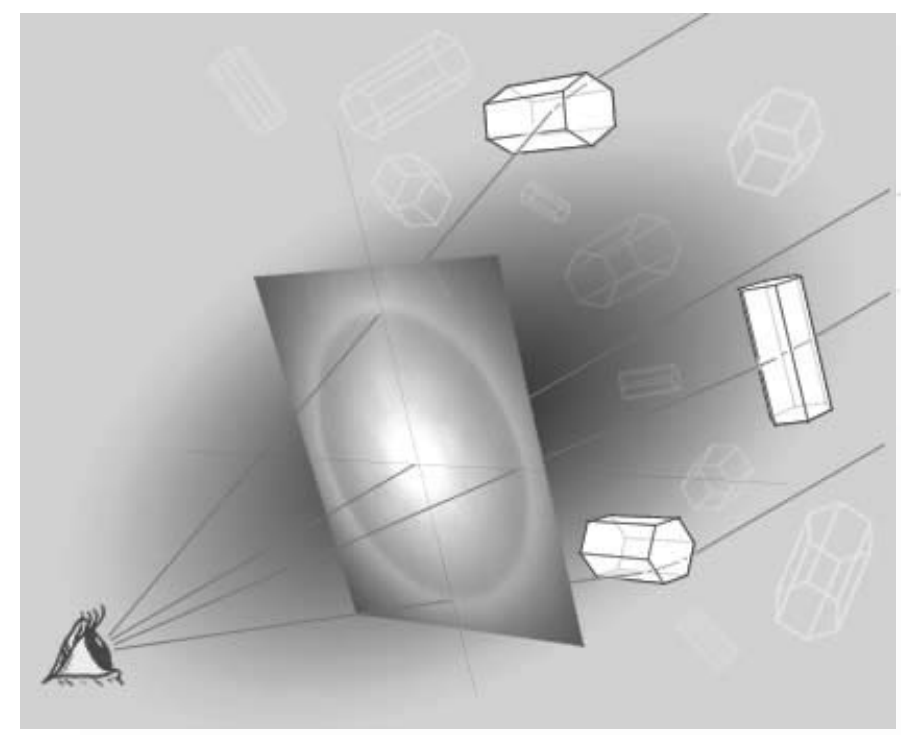

Figure 5 
bright object like the sun or moon; the light rays from the bright object are refracted at a minimum of $22^{\circ}$ through the crystals whose edges happen to be perpendicular to the plane (or all planes) between the luminous object and the observer's eye; the crystals, which function as prisms have a refracting angle of $60^{\circ}$ and thus will cause light to be deviated exactly $22^{\circ}$; crystals at $22^{\circ}$ from the eye of the observer will thus be illuminated; since the angle of refraction for every prism on every plane between the observer and the light source is exactly the same, the result is necessarily a circle. ${ }^{58}$

The history of this explanation is quite well understood. Restricting ourselves to a capsule summary of just the halo (and not wider phenomena like the rainbow, much less fields like optics), the most important advance after Aristotle was made by Descartes in his Meteorology (part of the Discourse on the Method). Descartes postulated that the cloud in which the halo appears consists of ice particles; he supposed that these were thicker in the middle than on the edges so that they would focus the light and diverge into a cone. Christiaan Huygens did experimental work with water drops that confirmed this, and he developed a theory of ice spheres and cylinders, providing the first exact quantitative theory of halo formation; it should be noted that this was one of the first major successes of early modern mathematical physics. Edme Mariotte posited that the columnar ice crystals acted as prisms. Thomas Young and Henry Cavendish posited specifically hexagonal prisms, and extrapolated Mariotte's prism hypothesis to the other halo phenomena (such as the larger halos and parhelia). As one extremely well-informed author puts it 'the basis of all current theories of the halos remains the same'..$^{9}$

Descartes begins his explanation of halos with the following observation: 'they are round, or nearly round, and always surround the sun or some other heavenly body; this shows that they are caused by some reflection or refraction whose angles are all nearly equal' ${ }^{60}$ His diagram

58 See, inter alia, R. S. Heath, A Treatise of Geometrical Optics (Cambridge: Cambridge University Press 1887), 349; W. J. Humphries, Physics of the Air (Philadelphia: The Franklin Institute 1920), 494. Note that not all edges have to be perpendicular, for some skewed rays contribute to the halo effect.

59 R. A. R. Tricker, Introduction to Meteorological Optics (New York: Elsevier 1970), 73

60 R. Descartes, Discourse on Method, Optics, Geometry, and Meteorology, translated by P. J. Olscamp (Indianapolis: Hackett 2001), 348 
(figure 6) ${ }^{61}$ essentially reproduces (without attribution of course) the diagram described by Aristotle, which he probably encountered in a renaissance or scholastic textbook.

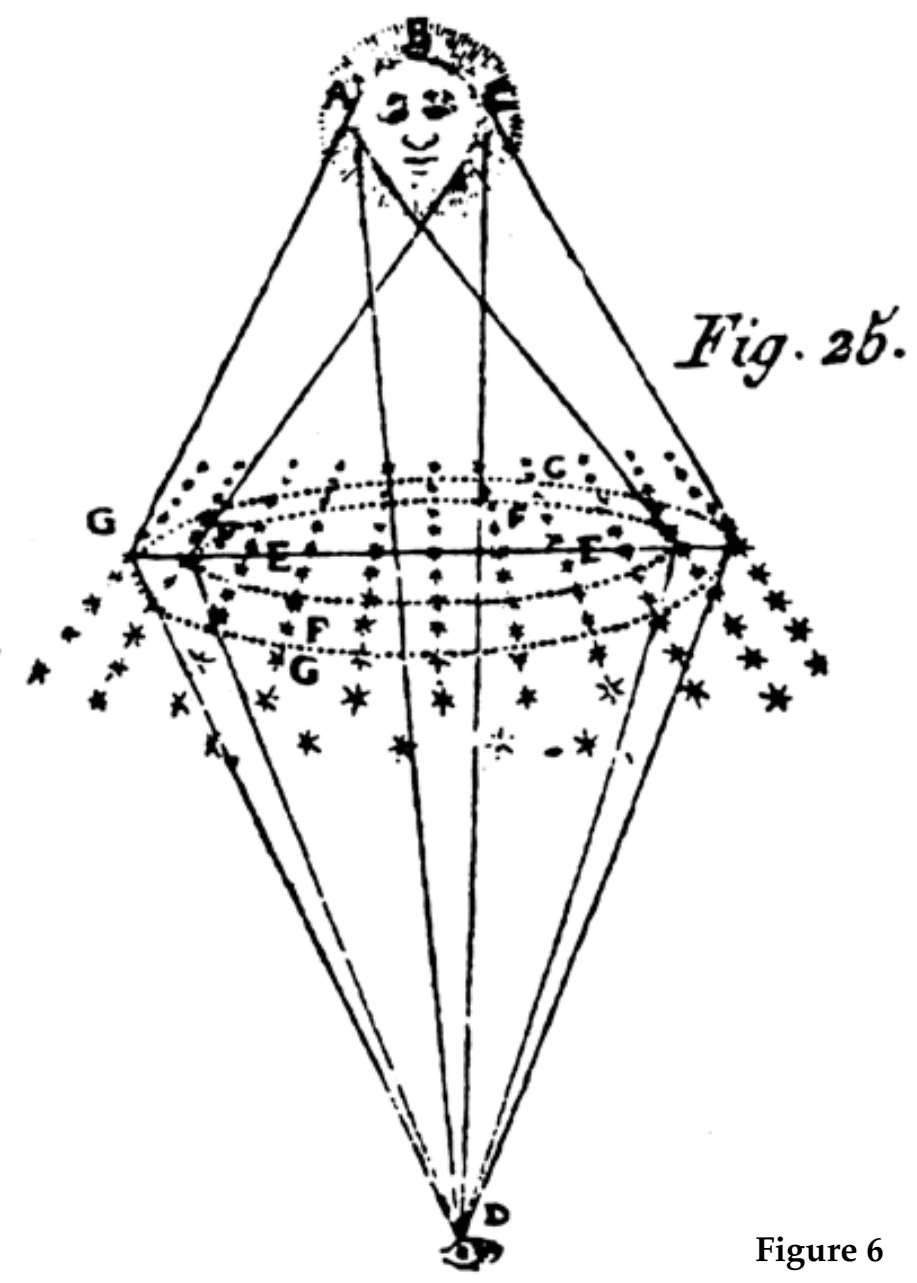

61 Descartes, Meteorology, 349 
Descartes' and his successors' refinements of Aristotle's diagram and explanation, due for the most part to a focus on the individual crystals and their prismatic properties, have without question added crucially to the modern theory, which owes its lucidity primarily to the work of Huygens, Marriotte, Young, and Cavendish. These improvements have been incorporated into modern diagrams and explanations, and have allowed us to go deeper than Aristotle's and Descrates' explanation and to say why exactly the light is refracted (or diffracted in the case of coronae) as it is. What we have now is a sound quantitative understanding, but this has been built on top of a very long history of attempts at an exact mathematical description and explanation of the phenomenon, and there is no question that these attempts begin with the explanation found in Meteorology III 2. Subsequent observation and theoretic studies have eliminated much of the mystery connected with the relatively mundane and frequent $22^{\circ}$ halo (although some very important questions remain unanswered). But it should be acknowledged that all modern theories, consciously or not, have been built on the foundation of Aristotle's account in the Meteorology, and in general on his method of combining geometrical and optical science in order to explain empirical meteorological data. Without the bold speculation that these appearances are not substantial but rather optical phenomena, and without a general theory of how mathematical facts might be related to empirical observations, and without the attempt to illustrate and explain the phenomena with the aid of a lettered geometrical diagram, there could be no understanding of halo phenomena along the lines offered by contemporary scientists.

It is hardly a coincidence, although it is rarely or never pointed out, that the three sciences Descartes used to exhibit his method were: Geometry, Optics, and Meteorology — precisely the subalternate sciences that Aristotle mentions in general contexts in the Posterior Analytics and employed in a concrete explanation in the Meteorology. What an excellent way to exhibit a use for mathematics in the explanation of a natural phenomenon. ${ }^{62}$

62 I am indebted in the first place to Les Cowley, whose informative and didactic website 'Atmospheric Optics' (www.atoptics.co.uk) inspired me to write this essay; I am also indebted to him for extensive comments on a draft, which have saved me from embarrassing errors and confusions with respect to the modern scientific understanding of halo phenomena. Of course the remaining shortcomings are entirely my own fault. The essay was also greatly improved by written comments 
Department of Philosophy

University of California, San Diego

9500 Gilman Drive

La Jolla, CA 92093-0119

U.S.A.

monte@ucsd.edu

on an earlier draft from James G. Lennox, Joseph Novak, Daryn Lehoux, Phillip Horky, and an anonymous referee for Apeiron. Thanks also to Jim Hankinson for oral feedback and editorial direction, and Roger Shiner for editorial management. I also benefitted from bibliographic suggestions from Adrienne Mayor, and oral comments from the audience of a UCSD science studies talk (especially Nancy Cartwright, Robert Westman, and Christian Wüthrich), as well as discussions with UCSD graduate and undergraduate students (especially Nat Jacobs, John Jacobson, and Dennis Jimenez). 
358 Monte Ransome Johnson 